\title{
Modelling the integrated effects of land use and climate change scenarios on forest ecosystem aboveground biomass, a case study in Taihe County of China
}

\author{
WU Zhuo ${ }^{1,2}$, ${ }^{*}$ DAI Erfu1 ${ }^{1}$ GE Quansheng ${ }^{1}$, XI Weimin ${ }^{3}$, WANG Xiaofan ${ }^{1,2,4}$
}

1. Key Laboratory of Land Surface Pattern and Simulation, Institute of Geographic Sciences and Natural Resources Research, CAS, Beijing 100101, China;

2. University of Chinese Academy of Sciences, Beijing 100049, China;

3. Department of Biological and Health Sciences, Texas A\&M University, Kingsville, Texas 78363, USA;

4. Key Laboratory of Land Use, Ministry of Land and Resources, China Land Surveying and Planning Institute, Beijing 100035, China

\begin{abstract}
Global and regional environmental changes such as land use and climate change have significantly integrated and interactive effects on forest. These integrated effects will undoubtedly alter the distribution, function and succession processes of forest ecosystems. In order to adapt to these changes, it is necessary to understand their individual and integrated effects. In this study, we proposed a framework by using coupling models to gain a better understanding of the complex ecological processes. We combined an agent-based model for land use and land cover change (ABM/LUCC), an ecosystem process model (PnET-II), and a forest dynamic landscape model (LANDIS-II) to simulate the change of forest aboveground biomass (AGB) which was driven by land use and climate change factors for the period of 2010-2050 in Taihe County of southern China, where subtropical coniferous plantations dominate. We conducted a series of land use and climate change scenarios to compare the differences in forest AGB. The results show that: (1) land use, including town expansion, deforestation and forest conversion and climate change are likely to influence forest AGB in the near future in Taihe County. (2) Though climate change will make a good contribution to an increase in forest $A G B$, land use change can result in a rapid decrease in the forest $A G B$ and play a vital role in the integrated simulation. The forest $A G B$ under the integrated scenario decreased by $53.7 \%$ (RCP2.6 + land use), 57.2\% (RCP4.5 + land use), and 56.9\% (RCP8.5 + land use) by 2050 , which is in comparison to the results under separate RCPs without land use disturbance. (3) The framework can offer a coupled method to better understand the complex and interactive ecological processes, which may provide some supports for adapting to land use and climate change, improving and optimizing plantation structure and function,
\end{abstract}

Received: 2016-08-30 Accepted: 2016-10-09

Foundation: National Basic Research Program of China (973 Program), No.2015CB452702; National Natural Science Foundation of China, No.41571098, No.41371196, No.41530749; National Key Technology R\&D Program, No.2013BAC03B04

Author: Wu Zhuo, PhD Candidate, specialized in climate change and simulation of LUCC. E-mail: wuz.14b@igsnrr.ac.cn "Corresponding author: Dai Erfu (1972-), PhD and Professor, E-mail: daief@igsnrr.ac.cn 
and developing measures for sustainable forest management.

Keywords: RCPs; plantation; forest aboveground biomass; ABM; LANDIS-II; Taihe County

\section{Introduction}

Land use and climate change are the two prongs of global change and global ecology, contributing to changes in both local environment and forest ecosystem services (Hansen et al., 2001; Schroter et al., 2005). Multiple human-induced global changes, such as climate change, land use change, deforestation and other global environmental changes are complex and are interacting in the context of a multi-system (e.g., climate system, land system, forest ecosystem). These changes are modifying the atmospheric composition and the land surface's landscape, resulting in a complex impact on the forest ecosystem (Karl and Trenberth, 2003; Foley et al., 2005). Traditionally, climate, land use, and forest ecological response studies have been operated relatively separately, dealing with specific questions in respective research fields on different space and time scales (Parmesan and Yohe, 2003; Drummond and Loveland, 2010; Rounsevell et al., 2012). However, as research continues, these factors separating studies cannot satisfy the needs of human-earth system coupling and multidisciplinary integrated development, nor can they keep up with the policy makers' overall planning (Schindler and Hilborn, 2015). Therefore, to better adapt to and mitigate the future global change, it is necessary to explore and anticipate the individual and combined impacts of land use and climate change on forest.

As a result of continued anthropogenic disturbances, climate change has and will continue to affect the forest ecosystem from species to communities, including tree species richness, forest productivity, forest composition and distribution, and forest biomass (Boisvenue and Running, 2006; Bertrand et al., 2011; Michaletz et al., 2014; Dai et al., 2016). Among them, the change of forest biomass is the most significant criterion for evaluating the quality of the forests and has been widely used in the studies of forest ecological responses to climate change and other disturbances (Fearnside, 2000; Mickler et al., 2002). In general, climate change and its impact on forest ecosystems show a long-term process (Payette et al., 1989). Much attention has been focused on the interaction between atmospheric composition changes (e.g., $\mathrm{CO}_{2}, \mathrm{~N}$ ) and the tree species or forest communities (Medlyn et al., 2001; Xu et al., 2007). However, compared with the long-term effects caused by climate change, land use change (such as urbanization, deforestation, farmland expansion and transition, and engineering construction) can bring more direct, short-term effects on forest landscape and forest biomass (Rudel et al., 2005). Due to the complex relationships between forest ecosystem, climate system and land system, it is difficult to explore and predict the key ecosystem characteristics except by going through coarse estimates (Gustafson et al., 2010). In recent years, however, multi-scale and multi-model approaches have provided a new method for some organizations, communities and researchers to deal with these comprehensive issues. For example, global land project (GLP) presented a framework that incorporates human behavior processes in land use and climate system models to quantitatively analyze dynamic changes in terrestrial ecosystems by using agent-based land use and land cover change models (ABM/LUCC) and some dynamic global vegetation models (DGVMs) (Rounsevell et al., 2012). And for another example, the European advanced terrestrial eco- 
system analysis and modeling (ATEAM) project proposed using multiple internally consistent scenarios and models to assess the vulnerability of agriculture, forestry, and other human sectors that rely on ecosystem services with respect to global change (Schröter et al., 2004). In terms of more specific issues for forest ecosystems, many studies have also been conducted at the regional or landscape levels. Nepstad et al. (2008) used global circulation models (GCMs), dynamic vegetation models and economic models to explore the interactions among ecosystems, economy and climate to make prospects for a near-term forest tipping point in the Amazon. Thompson et al. (2011) used the LANDIS-II model to evaluate regional forest growth and composition change in Massachusetts, USA over a period of 50 years. They found that, while climate change may enhance growth rates, it will be more than offset by land use, primarily by forest conversion for developed use. ABM has many advantages in simulating land use change and it is designed to integrate human decision processes into a location-specific context in order to explain patterns of land use and test the understanding of land use functions (Matthews et al., 2007). For forest landscape simulation, the LANDIS-II model is a forest disturbance and succession model that can simulate significant ecological characteristics of forested landscapes, such as tree composition, distribution, disturbances, and seed dispersal, as well as the spatial arrangement of aboveground biomass (AGB) (Scheller et al., 2007). Meanwhile, this model was specifically designed to address the effect of land use and climate change on forest landscape (Xu et al., 2007, 2011; Thompson et al., 2016). Based on the above, we combined an ABM/LUCC model, an ecosystem process model (PnET-II) and the LANDIS-II to simulate and analyze the variations in forest AGB under various land use and climate scenarios.

In southern China, the forested regions are vast, and the plantations are widely distributed in the hilly red soil region, which accounts for $63 \%$ of the total area and $62 \%$ of the total stocking volume of those in the whole of China (Liu et al., 2014). In the past decades, though the rapid expansion of plantations has made a significant contribution to industrial production and ecosystem services, several issues and challenges always exist, such as unitary tree species, low volumes in growing stock, etc. (Liu et al., 2011). At the same time, the development of plantations is under pressure from both changes. With the acceleration of urbanization and township in China nowadays, the demand for land is increasing and the corresponding climate change will exert intense pressure on the regional forest management (Rudel et al., 2005). In this paper, our objectives were (1) to estimate the land use changes, including the town expansion, deforestation and forest conversion in Taihe County, Jiangxi Province, China, (2) to build a research framework to explore the integrated and relative effects by using simply coupled models, and (3) to simulate the integrated effects of climate change and land use change on forest AGB under various scenarios over the next 40 years from 2010 to 2050. We chose this period for simulation based on following aspects. Firstly, land use changes are greatly influenced by policy which may change with economy, population and other environmental factors. In this study, we chose the relative recent period of 2010-2050 to simulate the land use change. Secondly, this period can also reflect an overall trend of climate change in the near future. So, we chose this period by considering the tradeoff of temporal scale effects between land use and climate change to simulate the integrated effects on forest ecosystem. 


\section{Materials and methods}

\subsection{Study area}

Our study area is Taihe County $\left(26.45^{\circ}-26.98^{\circ} \mathrm{N}, 114.95^{\circ}-115.33^{\circ} \mathrm{E}\right)$, which is located in south-central Jiangxi Province, a typical hilly red soil region of southern China (Figure 1). The total area of the study area is 266,700 ha, and the study area is a major component of the Jitai Basin. This area has a subtropical monsoon climate with mild winters (with a mean January temperature of $6.5^{\circ} \mathrm{C}$ ) and warm summers (with a mean July temperature of $29.7^{\circ} \mathrm{C}$ ), and the average annual temperature is $18.6^{\circ} \mathrm{C}$. The average annual precipitation is $1370 \mathrm{~mm}$, most of which (approximately 60\%) falls between March and June (Wang et al., 2011). The main land use type in the study area includes forest land, town land, farmland, river, and the other land. The total forest area is 163,200 ha, contributing $61.2 \%$ to the study area, and the area of plantations is 73,292 ha, which accounts for $44.9 \%$ of the total forested area according to forestry resource survey data in Jiangxi Province in 2009. The forests within the study area are comprised of 18 dominant species including: masson pine (Pinus massoniana), slash pine (Pinus elliottii), Chinese fir (Cunninghamia lanceolata), Chinese weeping cypress (Cupressus funebris), camphor tree (Cinnamomum camphora), zhennan (Phoebe zhennan), crenate gugertree (Schima superba), beautiful sweetgum (Liquidambar formosana), Chinese sassafras (Sassafras tzumu), eyer evergreenchinkapin (Castanopsis eyrei), myrsinaleaf oak (Cyclobalanopsis gracilis), fortune chinabells (Alniphyllum fortunei), farges evergreenchinkapin (Castanopsis fargesii), longpeduncled alder (Alnus cremastogyne), faber oak (Quercusfabri), shinybark birch (Betula luminifera), chinaberry (Melia azedarach) and poplar (Populus deltoids). The Qianyanzhou Experiment Station for Comprehensive Development of Natural Resources in the Red Earth Hilly Area (QYZ ecological station, see Figure 1) is also located within our study area.

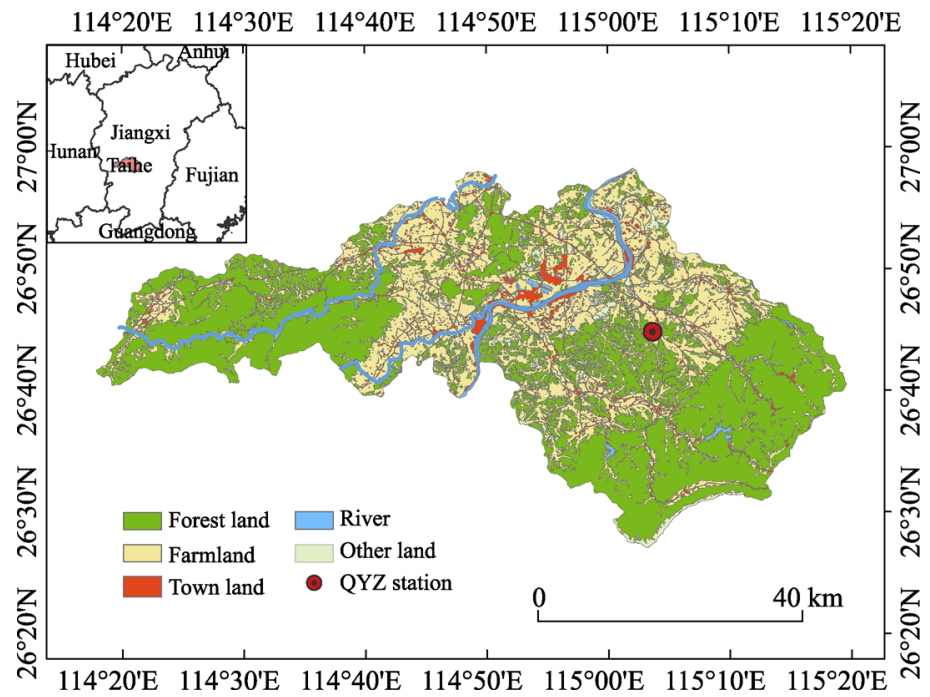

Figure 1 Location and land use types of Taihe County, Jiangxi Province, China. QYZ station: Qianyanzhou ecological station 


\subsection{Climate change}

The future climatic data were compiled from the projections of 21 climate models in the Coupled Model Intercomparison Project Phase 5 (CMIP5) of the World Climate Research Programme (WCRP) multi-model dataset, which was provided by the National Climate Center of China Meteorological Administration (http://www.climatechange-data.cn). The main climatic factors include monthly mean temperature, monthly maximum temperature, monthly minimum temperature, and monthly precipitation. In this study, the climatic data were under the Representative Concentration Pathways (RCPs) scenarios, including the RCP2.6, RCP4.5 and RCP8.5 scenarios from 2010 to 2050. From the climate prediction dataset, it can be found that the annual mean temperature will have a $1.09-1.73^{\circ} \mathrm{C}$ increase in our study area in all RCPs scenarios (Figure 2). However, due to the subtropical monsoon climate, the inter-annual variation of precipitation shows a slightly increasing trend and obvious fluctuation from 2010-2050 under various RCPs scenarios. In addition, we designed a control scenario by extrapolating current climate conditions, whereby the temperature and precipitation data were the means of the observations during the last 10 years (2001-2011) from the QYZ ecological station in our study area.
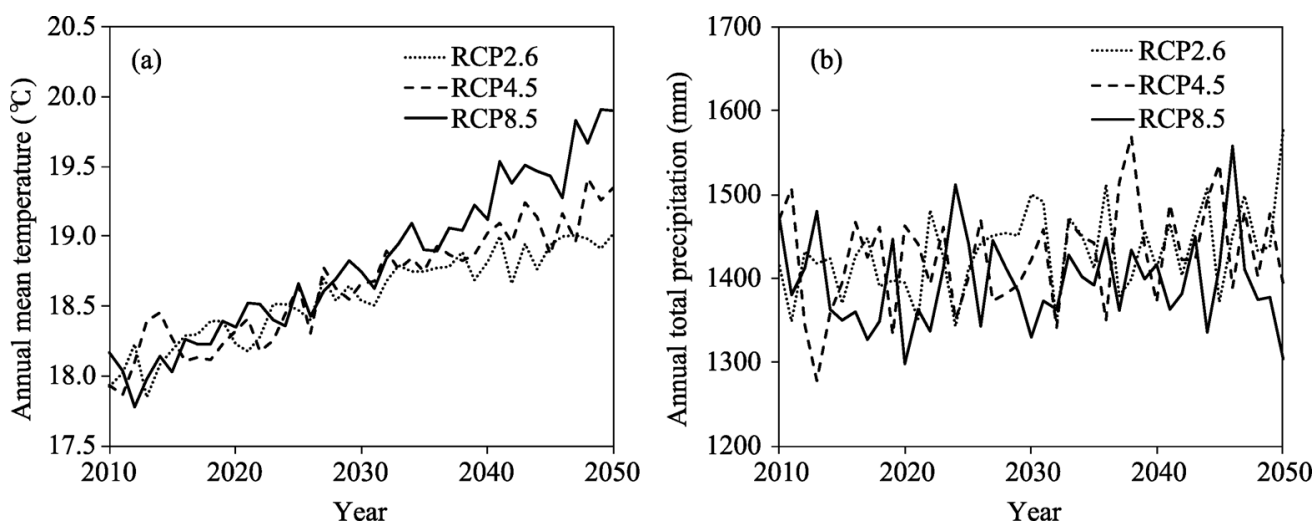

Figure 2 Variation trend of annual mean temperature and precipitation in the study area under RCPs scenarios from 2010 to 2050 . (a) annual mean temperature $\left({ }^{\circ} \mathrm{C}\right.$ ); (b) annual total precipitation (mm) under RCPs scenarios

\subsection{Land use change simulation}

In our study area, there are mainly four types of land use, including town land, forest land, farmland and other land. The land use data in 1990, 1995, 2000, 2005, and 2010 were obtained from the land and resources survey by the department of land and resources of Jiangxi Province, China. Based on these, we found that the land use types did not change dramatically, and land use changes mainly occurred as town land sprawl and forest land loss. Therefore, farmland and other land were not modeled in the future land use simulation, with their changes depending on the simulated results of forest land and town land. The town land sprawl was of interest in our study, as it had a close relationship with human activities and human decisions. In this study, we used a GIS-based agent based model built by Agent Analyst software. Agent Analyst is an open-source software developed to integrate an ABM development platform - the Recursive Porous Agent Simulation Toolkit (Repast) - within a 
GIS (ArcGIS). Agent Analyst is a mid-level integration tool that takes advantage of both modeling environments. Specifically, we used the modified and simplified urban growth model to investigate how the behavior of residential household agents affects landscape sprawl for Taihe County. In this model, there is a town center agent placed in the center of Chengjiang Town, which is the center of economy, politics and population in the study area. Residential household agents evaluated the utility by calculating a score for each sample cell's distance from the town center, the probability of development, and the importance of the resident agent placed on distance and development probability. The utility was calculated from several environmental variables. First of all, the distance from each cell to the town center (tcdist) was selected because the resident agent would give priority to the cells which were close to the town center. Secondly, the development probability for each cell was calculated by evaluating the physical condition and population. In this study, the development of town land use is limited by surroundings. For example, the development has a slope-limiting under 15 degrees, and land use type is not the water body in general. In the meantime, the area that is close to the roads may get a higher probability. We made a buffer of $30 \mathrm{~m}$ from the main roads, which have a higher development probability of town land use. In addition, the population in different zones had been considered. The population of different administrative division of the town units was standardized. These variables above, including slope, roads, and population, were weighted them equally and were overlaid to a map of development probability (devpro). Finally, we assumed that all the resident agents had the equal preference on the distance and development probability. This method can simplify the model code, as well as achieve our study objectives more directly. As a result, the agents may prefer cells that are closer to the town center and have a higher development probability. The utility formula is shown in Eq. 1:

$$
\text { Utility }=\left(1-\mid \beta_{p}-\text { devpro }\left.\right|^{\alpha_{p}}\right) \times\left(1-\left|\beta_{d}-t c d i s t\right|^{\alpha_{d}}\right)
$$

where devpro stands for the development probability, tcdist stands for the distance from each cell to the town center; $\beta_{d}$ represents that the resident agents prefer the cells closer to the town center, $\beta_{p}$ means that they prefer a higher development probability. Here, $\beta_{d}, \beta_{p}=1$. The importance resident agents place on development probability $\left(\alpha_{p}\right)$ and the distance to the town center $\left(\alpha_{d}\right), \alpha_{p}+\alpha_{d}=1$. For the sake of simplicity code, all resident agents have the same utility function and parameter values in this model. In terms of the inputs of the model, the land use map and the development probability map take the form of raster maps with a $100-\mathrm{m}$ resolution. The initial land use map is the rasterized land use data from 2010 . The development probability map is calculated by some limiting factors, as shown in Eq. 2:

$$
\text { Development probability }=f\left(\alpha_{p}, \beta_{s}, \gamma_{w}, \lambda_{r}\right)
$$

where $\alpha_{p}$ stands for the standardized population in respective administrative towns in Taihe County, and $\beta_{s}$ stands for the slope. In this study, we limited the developed cells' slope to less than 15 degrees. When the slope is above 15 degrees, the development probability is set to zero; $\gamma_{w}$ stands for the water body area, which is also defined as undeveloped area and the development probability set to 0 . $\lambda_{r}$ stands for the buffer of the roads, which is frequently affected by human activities, and the probability is set to 0.8 . The development probability is within the range of $0-1$, and the development probability map is shown in Figure 3. 


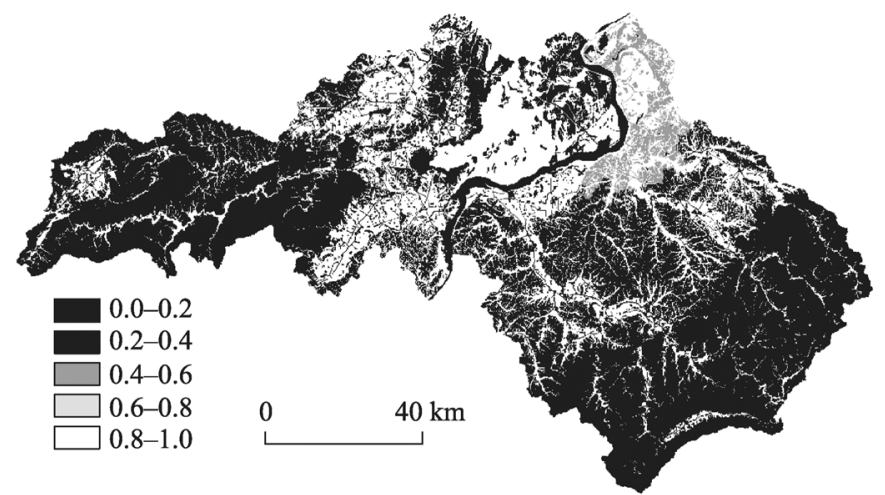

Figure 3 The map of development probability for resident agents to settle, where 0.0 means no development at all and 1.0 means full development

Based on the overall plans for land use in Taihe County from 2006 to 2020, we determined how many cells to develop for the resident agents in the future simulation. The overall plan for land use in part reflects the land use change policy in the near future, which indicates the choice tendency of the local government. The overall plan has a binding effect and a guiding function on the implementation of land use policies. Especially in China, the land use plan has a more profound effect and the local government plays a predominant role in the process of land use. Therefore, the land use plan data is relatively reliable to use as the basic data for the model in our study. The area of town land was 14,773 ha in 2010, and the total town planning area will reach 17,173 ha in 2020 according to the overall plan goal. Accordingly, about 240 new cells were selected at each time step (one year) for the resident agents to settle in and turn into town land. In this study, we assumed that the land use policy and developing rate will sustain and extrapolate current conditions in the coming decades up until 2050.

For deforestation and forest conversion modeling, we used the land use extension and biomass harvest extension from the LANDIS-II model. Land use extension can incorporate a sequence of maps depicting land use or land cover change into LANDIS-II simulations. Maps were developed from the output of the urban sprawl model in Agent Analyst. With this extension, the model can simulate how cohorts will be removed if changes in the land use or land cover results in forest loss. In addition, land use extension is integrated into the biomass harvest extension, resulting in corresponding land use and AGB changes. The harvest experiment in the simulation was designed to match the current forest management policy, which keeps ten percent for different forest management area at each time step (ten years) for the LANDIS-II model.

\subsection{Forest AGB simulation}

In this study, we used LANDIS-II and PnET-II to conduct the simulation of forest AGB. The LANDIS-II model is a cell-based spatially dynamic forest landscape model of disturbance, succession and management (Scheller et al., 2007). It can simulate forest dynamics by tracking the changes in species age cohorts, which is driven by species life history attributes, species establishment probability (SEP), maximum aboveground net primary production (ANPP), and spatial heterogeneity (Mladenoff and He, 1999). LANDIS-II is specifically designed to address the effects of climate change on forests and has been widely applied in 
analyzing complex interactions (Scheller and Mladenoff, 2005; Xu et al., 2009). In this study, we used the LANDIS-II model with the biomass succession extension, land use extension, and biomass harvest extension. With these extensions, LANDIS-II can address climate change and land use change effects on forest AGB (Gustafson et al., 2010; Thompson et al., 2011). The main inputs for LANDIS-II include spatial inputs (initial species maps, ecoregion maps and land use maps) and non-spatial inputs (species life history attributes, ANPP and SEP). The initial species map was derived from forestry resource survey data by the sub-compartment division of Jiangxi Province in 2009. The ecoregions map was divided into five ecoregions, four forested regions and one non-forested region, which were based on relatively homogeneous geomorphic forms (Figure 4). The parameters of the species life history attributes were mainly compiled from literature, plot investigation and consultations with local forestry experts (Chen et al., 1996; ECFC, 2000) (Table 1).

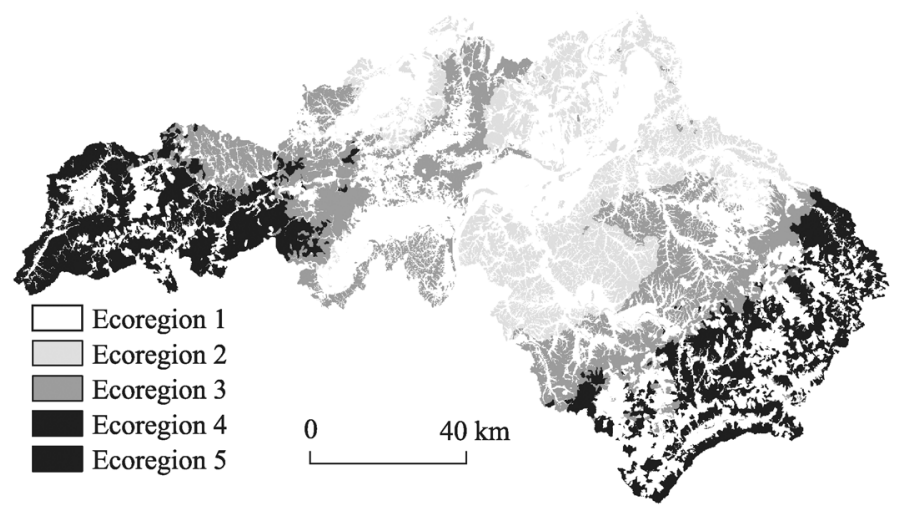

Figure 4 Ecoregions of the study area. Ecoregion 1 is non-forestland and un-active in our simulation. Ecoregions 2 to 5 stand for low hills (under $100 \mathrm{~m})$, medium hills $(100-250 \mathrm{~m})$, high hills $(250-500 \mathrm{~m})$ and mountains (above $500 \mathrm{~m}$ ), respectively

The ANPP and SEP for each species were derived from the PnET-II model. The PnET-II is a process based model for carbon and water balance in forest ecosystems (Aber and Federer, 1992). It can simulate the effect of climate change on forest photosynthesis by applying adjustable factors, including light, temperature, water availability, water vapor deficit and $\mathrm{CO}_{2}$ concentration (Xu et al., 2009). In this study, we applied version 5.1 of the PnET-II model to calculate the ANPP and SEP of 18 tree species under RCPs and a control scenario. The most primary parameters in PnET-II, such as the water-holding capacity (WHC) and photosynthetically active radiation (PAR), were based on observation in the QYZ ecological station. The other parameters were obtained from literature published for this area, including foliar nitrogen concentration (FolNCon) (Yu et al., 2014), minimum temperature for photosynthesis (PsnTMin) (Wu, 1984), optimum temperature for photosynthesis (PsnTOpt) (ECECA, 1989), and water use efficiency (WUE) (Sheng et al., 2011).

\subsection{Modelling framework}

To explore the integrated and relative effects of land use and climate change on forest AGB, we simply coupled the ABM/LUCC model, the PnET-II model and the LANDIS-II to build a framework and to combine the human system and the climate system (Figure 5). Firstly, we 
Table 1 Species life history attributes in Taihe County, Jiangxi Province, China

\begin{tabular}{|c|c|c|c|c|c|c|}
\hline \multirow[b]{2}{*}{ Species } & \multirow[b]{2}{*}{ Common name } & \multirow{2}{*}{$\begin{array}{c}\text { Longev- } \\
\text { ity } \\
\text { (year) }\end{array}$} & \multirow{2}{*}{$\begin{array}{c}\text { Sexual } \\
\text { maturity } \\
\text { (year) }\end{array}$} & \multirow{2}{*}{$\begin{array}{c}\text { Shade } \\
\text { tol. }\end{array}$} & \multicolumn{2}{|c|}{ Seed dispersal dist. } \\
\hline & & & & & $\begin{array}{c}\text { Effec- } \\
\text { tive }(\mathrm{m})\end{array}$ & $\begin{array}{l}\text { Maxi- } \\
\operatorname{mum}(\mathrm{m})\end{array}$ \\
\hline Cunninghamia lanceolata & Chinese fir & 200 & 10 & 1 & 200 & 500 \\
\hline Cupressus funebris & Chinese weeping cypress & 500 & 35 & 2 & 70 & 200 \\
\hline Pinus massoniana & Masson pine & 200 & 10 & 1 & 200 & 500 \\
\hline Pinus elliottii & Slash pine & 200 & 10 & 1 & 200 & 500 \\
\hline Schima superba & Crenate gugertree & 300 & 20 & 5 & 20 & 200 \\
\hline Cinnamomum camphora & Camphor tree & 1000 & 15 & 4 & 50 & 120 \\
\hline Phoebe zhennan & Zhennan & 1000 & 50 & 5 & 40 & 120 \\
\hline Castanopsis eyrei & Eyer evergreenchinkapin & 200 & 20 & 5 & 50 & 120 \\
\hline Castanopsis fargesii & Farges evergreenchinkapin & 150 & 30 & 5 & 60 & 250 \\
\hline Quercus fabri & Faber oak & 120 & 15 & 4 & 20 & 200 \\
\hline Cyclobalanopsis gracilis & Myrsinaleaf oak & 200 & 7 & 4 & 20 & 50 \\
\hline Liquidambar formosana & Beautiful sweetgum & 130 & 8 & 3 & 100 & 375 \\
\hline Betula luminifera & Shinybark birch & 100 & 15 & 2 & 150 & 400 \\
\hline Alnus cremastogyne & Longpeduncled alder & 125 & 5 & 3 & 15 & 60 \\
\hline Alniphyllum fortunei & Fortune Chinabells & 120 & 15 & 2 & 250 & 500 \\
\hline Sassafras tzumu & Chinese sassafras & 120 & 20 & 3 & 50 & 150 \\
\hline Melia azedarach & Chinaberry & 80 & 5 & 2 & 200 & 400 \\
\hline Populusdeltoids & Poplar & 90 & 10 & 2 & 150 & 500 \\
\hline
\end{tabular}

Notes: Shade tol. stands for the species' tolerance to shade. The value is an integer between 1and 5, where 1 means the least tolerance and 5 means the most tolerance. Seed dispersal dist. stands for the species' effective or maximum distance for dispersing seeds.

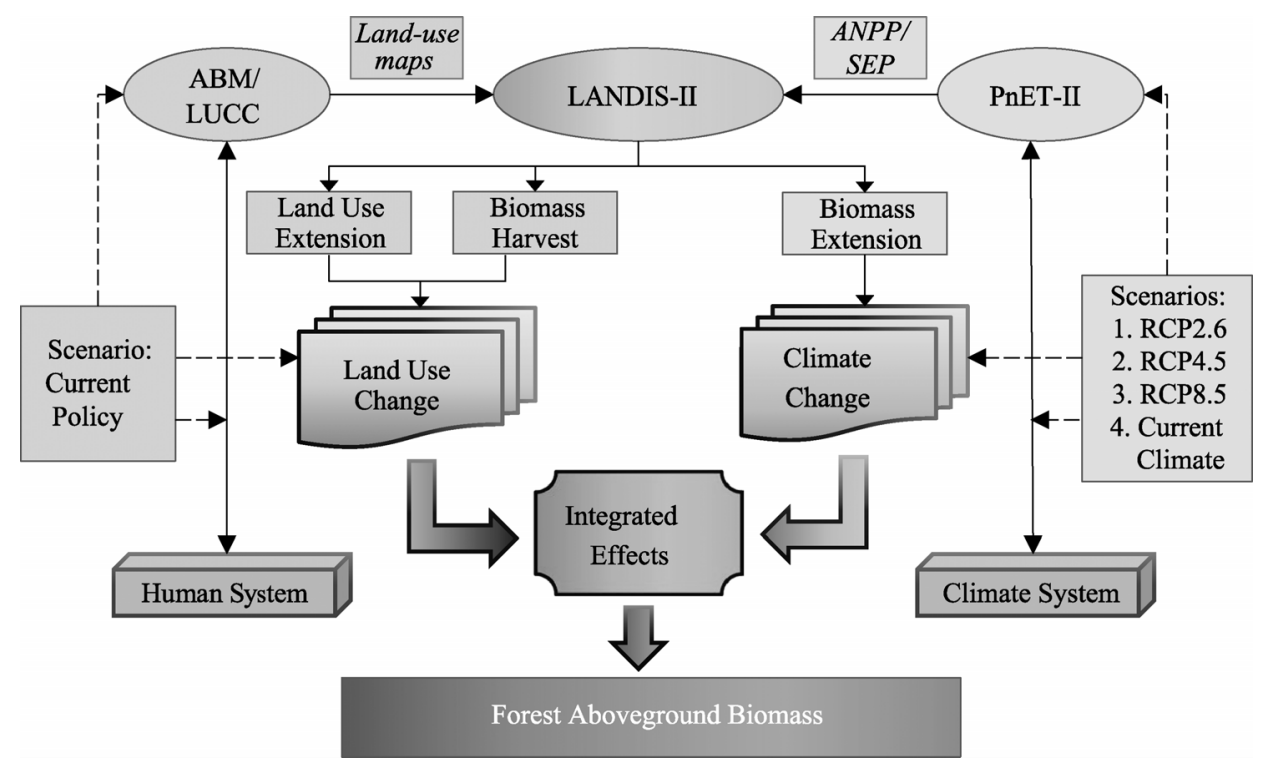

Figure 5 The framework for the integrated effects of land use and climate change on forest AGB

used the ABM/LUCC model to simulate the development of town land under the current land use policy. A series of land use maps were created from the output of the ABM model, as well as the input for land use extension for LANDIS-II. Secondly, we used the PnET-II 
model to calculate the ANPP and SEP for tree species under various climate scenarios, including RCP2.6, RCP4.5, RCP8.5, and a current climate (CC) scenario, as well as the inputs for the biomass succession extension of LANDIS-II. Finally, the LANDIS-II model was used as the core of the framework to simulate the forest AGB change under the pressure of human and climate factors. This framework offers a coupled method to better understand the interaction of ecological processes, and it may give some supports for improving and optimizing the plantations' structure and function.

\section{Results}

\subsection{Land use change modelling}

The results of the town land change under the ABM/LUCC model is shown in Figure 6. In this section, we are only interested in the town land sprawl, so the output maps are shown as town land over the upcoming 40 years. The results show area percentages of town land in 2020, 2030, 2040 and 2050 account for $6.4 \%, 7.3 \%, 8.2 \%$ and $9.0 \%$ of the total area, respectively. Rapid town land expansion is built on the current town center, which forms an overall sprawling trend of the town center into the surrounding area. The development of town land occurs in Chengjiang Town, which has the highest population in Taihe County. In addition, the results show that urban and town fringe is the transition belt, which is the most active portion of the town land sprawl process. The spatial pattern of the town land development reflects the rules and behaviors of the decision-making of the resident agents. They prefer to settle in areas closer to the town center.

(a) 2020

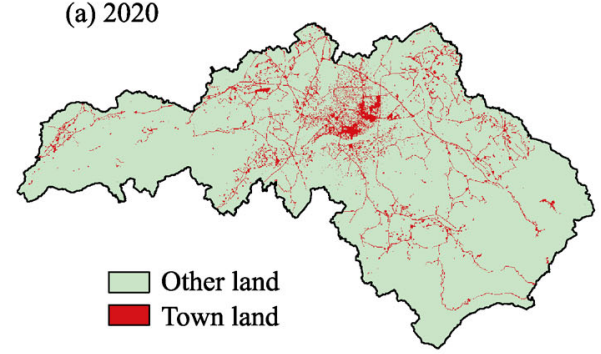

(c) 2040

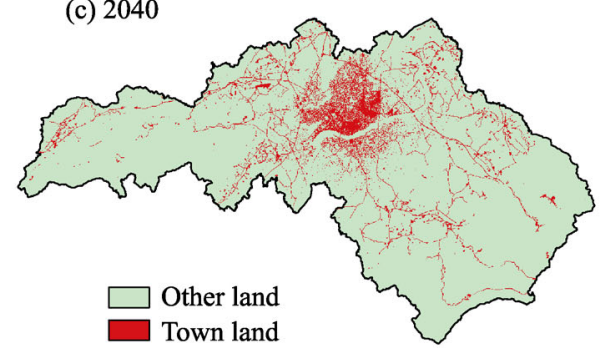

(b) 2030

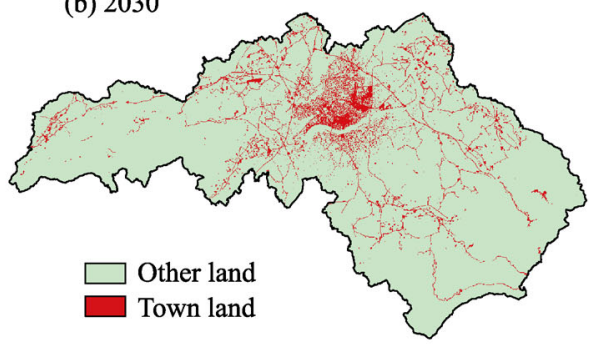

(d) 2050

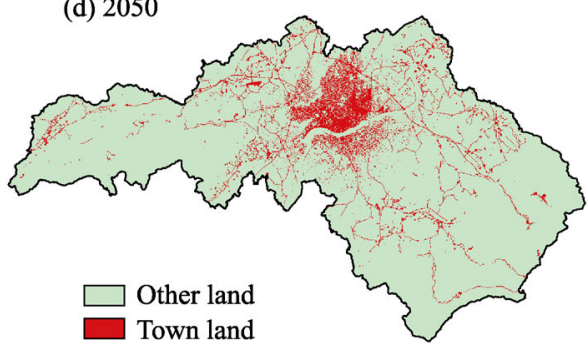

Figure 6 The results of town land change from the ABM/LUCC model

\subsection{ANPP}

The ANPP from the PnET-II model is an important parameter and offers important input for 
forest AGB calculation in the LANDIS-II model. Therefore, the ANPP change is of interest in this section and the ANPP change for the 18 tree species under the three RCPs scenarios is shown in Figure 7. The ANPP under the current climate scenario is unchanged during the simulation, so the results were not shown here. The mean values of the ANPP are calculated from the mean values in four active ecoregions from ecoregion 2 to 5 . The results of the simulation show that the overall trend of the ANPP for all species increases during 2010-2050, and the ANPP of broad-leaved species is significantly higher than that of coniferous species. Under different climate change scenarios, the variation in the ANPP shows a significant difference between species, especially for certain broad-leaved species, such as crenate gugertree, eyer evergreenchinkapin and farges evergreenchinkapin. Under the RCP2.6 scenario, the range of the ANPP for all species is $489 \mathrm{~g} \mathrm{~m}^{-2} \cdot \mathrm{yr}^{-1}$ (Chinese weeping cypress) to $1043 \mathrm{~g} \mathrm{~m}^{-2} \cdot \mathrm{yr}^{-1}$ (eyer evergreenchinkapin). By 2050, the percentage of the increase for each species is in the range of $5.7 \%$ (Chinese fir) to $12.5 \%$ (eyer evergreenchinkapin). Under RCP4.5 scenario, the range of the ANPP for all species is $483 \mathrm{~g}$ $\mathrm{m}^{-2} \cdot \mathrm{yr}^{-1}$ (Chinese weeping cypress) to $1097 \mathrm{~g} \mathrm{~m}^{-2} \cdot \mathrm{yr}^{-1}$ (eyer evergreenchinkapin). By 2050, the percentage of increase for each species is in the range of $7.7 \%$ (Chinese fir) to $23.4 \%$ (eyer evergreenchinkapin). Under the RCP8.5 scenario, the range of the ANPP for all species is $483 \mathrm{~g} \mathrm{~m}^{-2} \cdot \mathrm{yr}^{-1}$ (Chinese weeping cypress) to $1143 \mathrm{~g} \mathrm{~m}^{-2} \cdot \mathrm{yr}^{-1}$ (eyer evergreenchinkapin). By 2050, the percentage of increase for each species is in the range of $6.9 \%$ (Chinese fir) to $26.5 \%$ (eyer evergreenchinkapin). The forest AGB is influenced by many factors, such as ANPP, spatial distribution and SEP. The variation on ANPP is the dominant factor to affect the forest biomass, reflecting the AGB accumulation rate for different species. In terms of 18 species in our study area, the rate of change for each species from 2010 to 2050 was selected to show the effect of ANPP on forest AGB. The main tree species includes eyer evergreenchinkapin, chinaberry, longpeduncled alder, shinybark birch, faber oak and camphor tree. The effect degree of ANPP on forest AGB for these tree species gradually increase under RCP2.6, RCP4.5 and RCP8.5 scenarios.

\subsection{Forest AGB}

In order to ensure that the simulated result of forest AGB is relatively correct, we first compared the simulated and investigated values with the first year in order to validate the LANDIS-II simulation results. The investigated values come from the observational stand volume at each forest sub-compartment from the forestry inventory data. The method for converting between AGB and stock volume is referenced from Fang et al. (2001). The biomass expansion factor (BEF) was calculated as a function of stand timber volume (x), BEF = $\mathrm{a}+\mathrm{b} / \mathrm{x}$, where $\mathrm{a}$ and $\mathrm{b}$ are constants for a specific forest type (Fang et al., 2001). These variables for specific species were obtained through field measurements and from previous studies in the area (Wu et al., 2011). Specifically, five hundred sub-compartments were randomly selected as the verification points, which were based on the distribution of the main species in our study area (Figure 8a). The results showed a positive linear correlation between the simulated and investigated values $\left(R^{2}=0.6463, p<0.001\right)$, which indicated that the method's feasibility and the simulation results can be considered reliable (Figure $8 \mathrm{~b}$ ). 

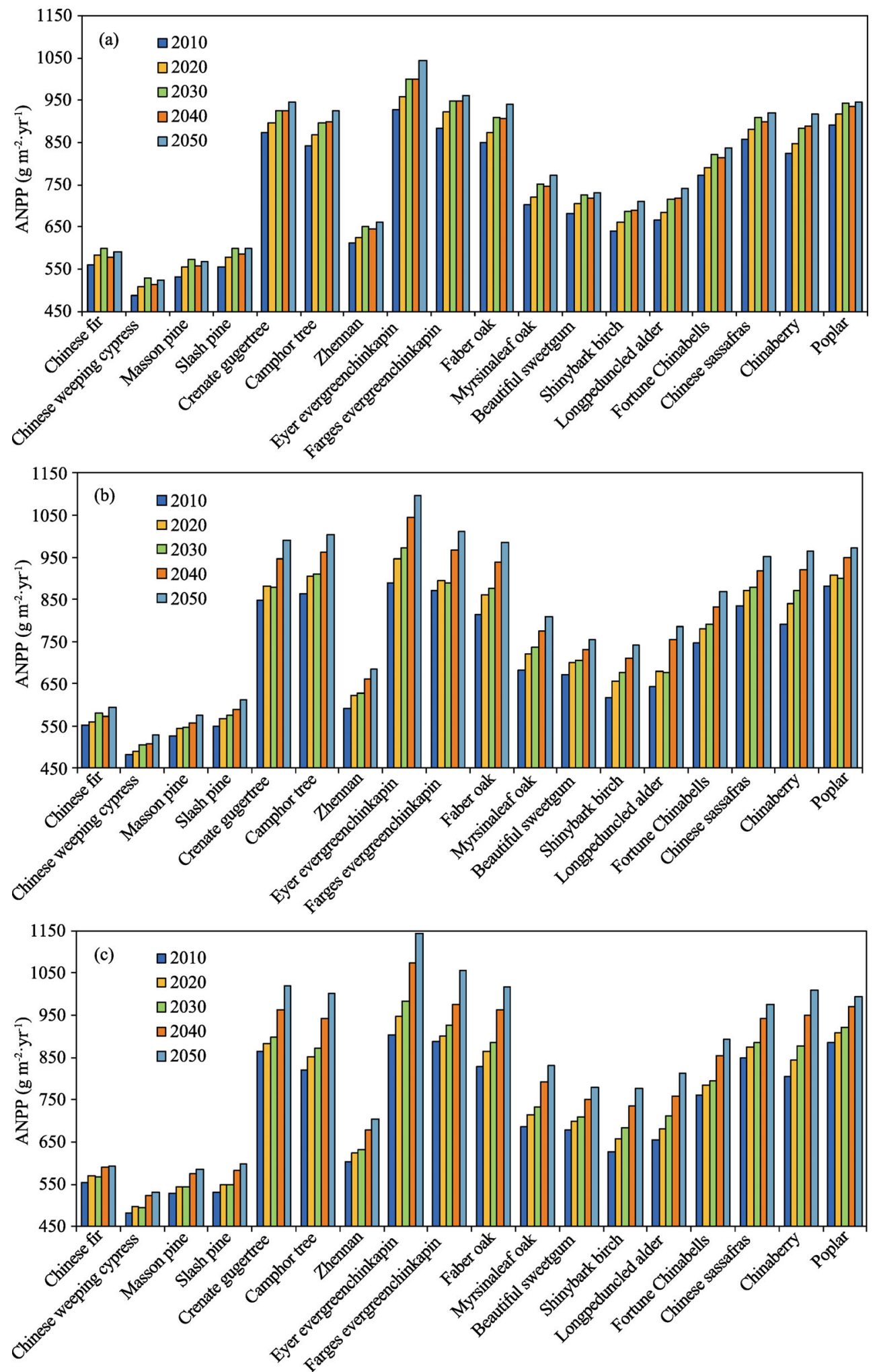

Figure 7 Aboveground net primary production (ANPP) for 18 species simulated by PnET-II under RCPs scenarios. (a) RCP2.6; (b) RCP4.5; (c) RCP8.5 

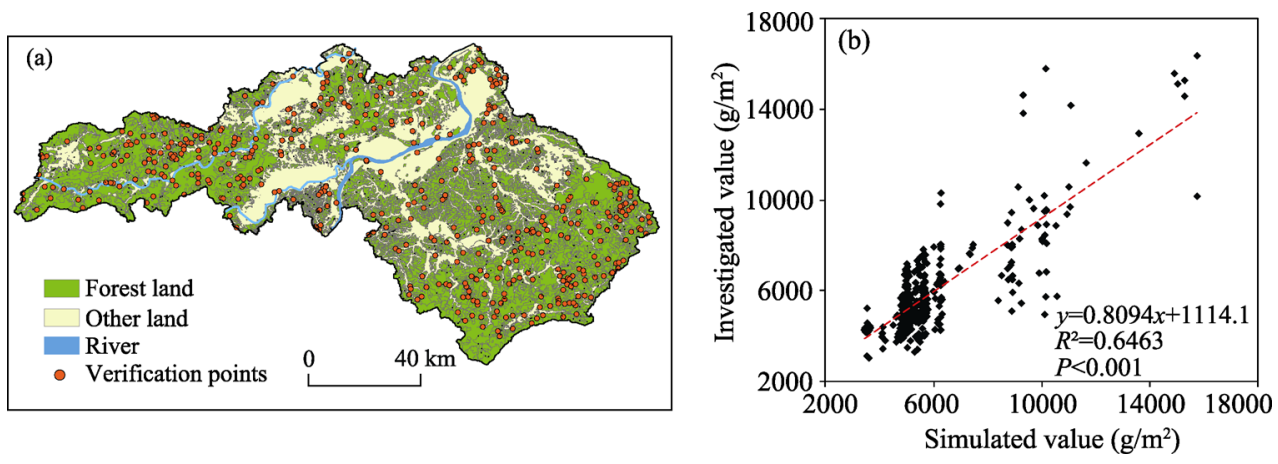

Figure 8 Spatial distribution of the points for model validation and the comparison between simulated and investigated values of forest $\mathrm{AGB}$

The forest AGB of the different tree species simulated by the LANDIS-II model under various scenarios is shown in Figure 9. The results show that all the forest AGB increase under the CC, RCP2.6, RCP4.5 and RCP8.5 scenarios from 2010 to 2050 (shown as the blue histogram in Figure 9). However, the results of the forest AGB show initial increase and then decrease under all land use and integrated scenarios (shown as the red histogram in Figure 9). As to the climate change, variation in the AGB shows a difference between various climate scenarios. By 2050, the forest AGB under CC, RCP2.6, RCP4.5 and RCP8.5 increases by $2965.9 \mathrm{~g} \mathrm{~m}^{2}, 3163.1 \mathrm{~g} \mathrm{~m}^{2}, 3281.1 \mathrm{~g} \mathrm{~m}^{2}$ and $3416.4 \mathrm{~g} \mathrm{~m}^{2}$, respectively. As to the isolated effect of land use, the forest AGB increases to $8109.3 \mathrm{~g} \mathrm{~m}^{2}$ in 2020 , then decreases to $6441.2 \mathrm{~g}$ $\mathrm{m}^{2}$ by 2050 only under the land use scenario. In terms of the integrated effect of land use and climate change, the results show an increase first, and then show a decreasing trend after 2020 under land use that is integrated with RCPs scenarios. When compared to the results under separate RCPs without land use disturbance, the forest AGB under the integrated scenario decreases by $53.7 \%$ (RCP2.6+land use), 57.2\% (RCP4.5+land use), and 56.9\% (RCP $8.5+$ land use), respectively by 2050 . Land use change plays a vital role in the integrated simulation. It has a more significant effect on forest AGB than climate change, and this effect will become more noticeable as the simulation time progresses.

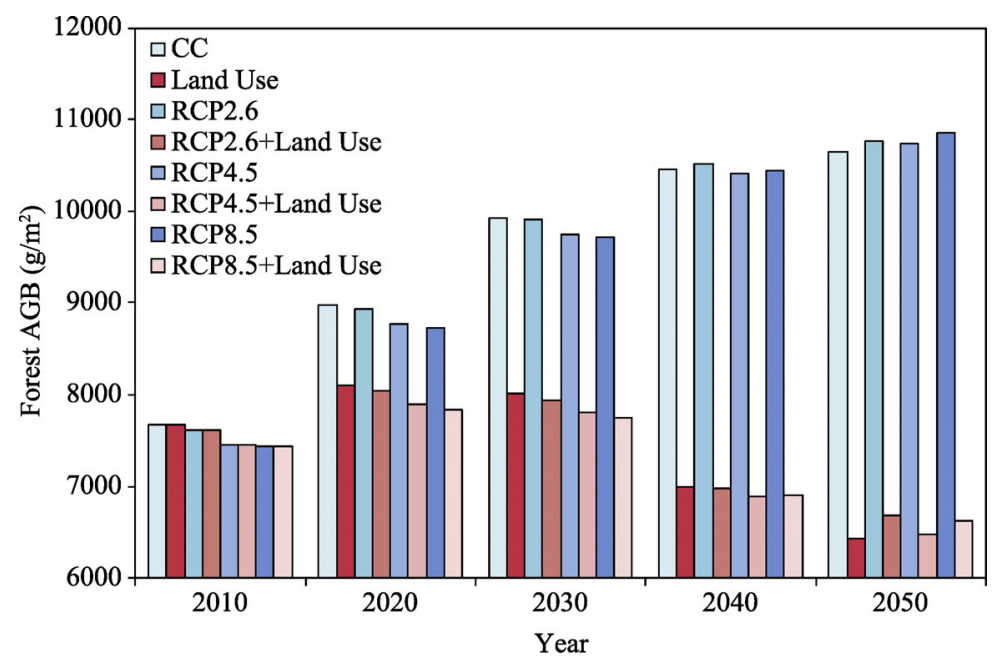

Figure 9 Forest AGB of the total forest area under various scenarios. CC: current climate scenario 


\section{Discussion}

\subsection{Results interpretation}

Our results suggest that land use and climate change is likely to significantly change forest AGB in our study area under various scenarios. Land use change, including town sprawl and harvest, makes a great contribution to the integrated effects and becomes the dominant factor in the simulation. These simulation results show consistence with the results of Thompson et al. (2011) and Gustafson et al. (2010). Thompson et al. (2011) found in Massachusetts, USA, while climate change may enhance growth rates, this will be more than offset by land use. Gustafson et al. (2010) also found that the direct effects of climate change in south-central Siberia are not as significant as timber harvest and other disturbances. For the simulation results of land use change, primarily forest conversion is the town land sprawl. We used the simplified ABM/LUCC model to simulate this conversion process of land use. The results help to specify the behavioral rules of individuals, identify the situations in which the agents reside, and determine possible outcomes according to the appropriate contexts. From an object-oriented point of view, these resident agents are self-directed objects, and their evaluation of the utility of the landscape location will influence their actions. The environmental factor is also an important contributor to ABM in this study. This method can directly represent the interior driving factors of land use change. According to our results, population and the physical environment are the two main factors that influence the agents' decisions. For the ANPP results, we found that forest productivity increased with temperature and precipitation in the subtropical monsoon climate zone under RCPs, which shows consistence with the result of Mi et al. (2008). Except for temperature and precipitation, change in other environmental factors also leads to ANPP change. For example, the changing atmospheric concentrations, such as $\mathrm{CO}_{2}$ (Wittig et al., 2005), $\mathrm{O}_{3}$ (Cojocariu et al., 2005) and $\mathrm{N}$ (Huang et al., 2014), may also affect forest productivity. In our study, we incorporated the effect of $\mathrm{CO}_{2}$ concentrations on the stomata conductance of different species. However, we did not consider the effects of $\mathrm{CO}_{2}$ fertilization on ANPP.

During simulation, the forest AGB accumulation is calculated by the ecosystem process rates and the quantity of aboveground living biomass for each tree species-age cohort without regard to disturbances (Scheller and Mladenoff, 2004). The biomass module conducted three process rates, ANPP, aboveground mortality, and woody biomass decomposition (Scheller and Mladenoff, 2005). These critical calculations and assumptions can help to implement the coarse simulation at the forest landscape scale (Scheller et al., 2007). As to the disturbances in our simulation, they are land use change (primarily town land sprawl and forest transition), climate change (primarily temperature and precipitation) and forest harvest (biomass removal). In the simulation, the biomass accumulation has a positive correlation with the increase of temperature and precipitation, irrespective of the land use change. This increasing trend of AGB is consistent with the results of Wu et al. (2011). Under all land use scenarios, the total forest AGB first experiences a slight increase and then quickly decreases. Forest transition and tree species removal that is caused by town land sprawl, and by plantation timber harvest done every ten years have resulted in a sharp decrease in the total forest AGB. These human-induced actions can result in even more direct influence on the forest AGB than climate change and biomass accumulation. 


\subsection{Uncertainties and limitations of simulating the integrated effects}

Land, climate and forest are interacting and are in the process of mutual restraint in the multisystem. Land system change is mainly caused by anthropogenic activity, which is accompanied by a series of forest landscape changes, including forest transitions, deforestation, forest conversion and reforestation (Rudel et al., 2005). Climate system change is also affected by anthropogenic activity and land use change, and it has effect and feedback mechanisms involved with the forest and the climate (Karl and Trenberth, 2003). For the forest ecosystem, spatial interactive processes, succession, disturbances, migration and transition occurred simultaneously (Hansen et al., 2001; Cottenie, 2005). Therefore, it is difficult to study longtime successive responses of this integrated effect on the forest at the landscape scale.

In this study, we offer a framework to explore the integrated and relative effects by using some simply coupled models. This framework can help us to assemble the models for different systems to conduct the integrated effects on forests, and to gain a better understanding of the complex, interacting ecological processes. However, there are also uncertainties and limitations of simulating the integrated effects in our study. Firstly, uncertainties exist in the data and in the parameterization process, which is limited by the available data and the literature. For climate data, the RCPs dataset resulting from the multi-model ensemble is still an important issue, though it is more acceptable than a single model (Tebaldi and Knutti, 2007). In addition, the accuracy of climate data is hard to obtain by spatial resolution at the regional and landscape scale. As to parameterization for the PnET-II and LANDIS-II, a large amount of tree species life history parameters may potentially arouse some uncertainty in the simulation. Even though these uncertainties and limitations are inevitable in the simulation process, our results are still credible based on the forestry survey data, plot investigation, model validation, and consultation with local forestry experts. Secondly, the limitations in the simulation were derived from the models. In this study, we used the highly simplified ABM/LUCC model. ABM is based on the complexity theory and can represent feedback in multilevel systems where the higher and lower levels simultaneously influence and limit one another (Yu et al., 2011). Meanwhile, the agents in the modeling are intelligent, so they can be influenced by the environment and by changes in the behavior of other agents. In order to simplify the code in the Agent Analyst and easily achieve our goals, we only concentrated on the resident agents and the town land change. The humans are the main actors in land use and other activities, and they are as well as the main sources of uncertainty in the simulation. The selection mechanism of human activities to land use will change with the physical condition and the relationship between different agents. In our study, we ignored some complex interaction process between agents which may lead to some uncertainty. However, this method can bring some conveniences for modeling in turn, and can make our study objectives to be achieved. The future studies should be improved to reduce uncertainty. (1) Differences of agent types should be considered to simulate the real world as much as possible. The main agent types should be selected depending on the specific research goals. (2) The key selection activities of different agents should be screened based on the research goals. We should consider the interaction and mutual influence between the agents. (3) The environmental and economic factors will change over time. This point should also be included 
and the extreme events can be added in the future simulation. (4) We should build the agent's self-learning mechanism according to the change of the agents and the environment, so as to find a balance between the reality and simulation to reduce uncertainty. For the other ecological models, the PnET-II and LANID-II models are also the simplifications of complex ecosystem processes. In terms of LANDIS-II, the model simulates broad spatial and long temporal scale dynamics for cells that incorporate species not with individual stems but with cohorts (Scheller et al., 2007). Finally, the coupled simulation that dealt with the integrated effects was based on some reasonable assumptions. For example, the species life-history attribute parameters and the landscape heterogeneity (e.g. landform, soil texture hydrologic conditions and phenology) would not change with time. Moreover, although the RCPs scenarios were developed from human activities like land use effect, we assumed that land use change was not affected by climate change, which could lead to some uncertainties in the simulation. Though there are cumulative uncertainties and limitations in simulating the integrated effects, we considered these to be trade-offs between the technical and ecological insights. Our objective is not to predict the forest biomass precisely in the near future, but to explore the change of forest landscape under multiple factors, which is a new exploration for the comprehensive simulation. This framework has scientific significance in the study of the effect of land use and climate change on forest landscape.

\section{Conclusions}

From our study we can draw the following conclusions. (1) Land use (including town expansion, deforestation and forest conversion) and climate change are likely to influence forest AGB in the near future in Taihe County. (2) Though climate change will make a good contribution to the forest AGB increase, land use change can result in a rapid decrease in the forest $\mathrm{AGB}$ and play a vital role in the integrated simulation. Under the integrated scenario, forest AGB decreased by 53.7\% (RCP2.6+land use), 57.2\% (RCP4.5+land use), and 56.9\% (RCP8.5+land use) by 2050, which is in comparison to the results under separate RCPs. (3) The framework for simulating the integrated effects on forest AGB can offer a coupled method to gain a better understanding of the complex, interacting ecological processes.

\section{References}

Aber J D, Federer C A, 1992. A generalized, lumped-parameter model of photosynthesis, evapotranspiration and net primary production in temperate and boreal forest ecosystems. Oecologia, 92: 463-474.

Bertrand R, Lenoir J, Piedallu C et al., 2011. Changes in plant community composition lag behind climate warming in lowland forests. Nature, 479: 517-520.

Boisvenue C, Running S W, 2006. Impacts of climate change on natural forest productivity: Evidence since the middle of the 20th century. Global Change Biology, 12: 862-882.

Chen Xiaoyang, Li Wengang, Pan Qimin et al., 1996. Studies on spacial distribution and the spread distance of pollen in Chinese fir seed orchards. Journal of Beijing Forestry University, 18: 24-30. (in Chinese)

Cojocariu C, Escher P, Häberle K H et al., 2005. The effect of ozone on the emission of carbonyls from leaves of adult Fagus sylvatica. Plant, Cell and Environment, 28: 603-611.

Cottenie K, 2005. Integrating environmental and spatial processes in ecological community dynamics. Ecology Letters, 8: 1175-1182.

Dai Erfu, Wu Zhuo, Ge Quansheng et al., 2016. Predicting the responses of forest distribution and aboveground 
biomass to climate change under RCPs scenarios in southern China. Global Change Biology, 22: 3642-3661. doi: $10.1111 /$ gcb.13307.

Drummond M A, Loveland T R, 2010. Land-use pressure and a transition to forest-cover loss in the eastern United States. BioScience, 60(4): 286-298.

Editorial Committee of Encyclopedia of Chinese Agriculture (ECECA), 1989. Encyclopedia of Chinese Agriculture: Forestry Volume. Beijing: China Agriculture Press. (in Chinese)

Editorial Committee of Forest of China (ECFC), 2000. Forest in China (Vol. 2 \& 3). Beijing: China Forestry Publishing House. (in Chinese)

Fang Jingyun, Chen Anping, Peng Changhui et al., 2001. Changes in forest biomass carbon storage in China between 1949 and 1998. Science, 292: 2320-2322.

Fearnside P M, 2000. Global warming and tropical land-use change: Greenhouse gas emissions from biomass burning, decompotition and soils in forest conversion, shifting cultivation and secondary vegetation. Climatic Change, 46: 115-158.

Foley J A, Defries R, Asner GP et al., 2005. Global consequences of land use. Science, 309: 570-574.

Gustafson E J, Shvidenko A Z, Sturtevant B R et al., 2010. Predicting global change effects on forest biomass and composition in south-central Siberia. Ecological Applications, 20: 700-715.

Hansen A J, Neilson R P, Dale V H et al., 2001. Global change in forests: Responses of species, communities, and biomes. BioScience, 51(9): 775-779.

Huang Wenjuan, Zhou Guoyi, Liu Juxiu et al., 2014. Shifts in soil phosphorus fractions under elevated $\mathrm{CO}_{2}$ and $\mathrm{N}$ addition in model forest ecosystems in subtropical China. Plant Ecology, 215: 1373-1384.

Karl T R, Trenberth K E, 2003. Modern global climate change. Science, 302: 1719-1723.

Liu Shirong, Wu Shuirong, Wang Hui, 2014. Managing planted forests for multiple uses under a changing environment in China. New Zealand Journal of Forestry Science, 44(Suppl 1): S3.

Liu Shirong, Lin Yong, Zhang Yuandong et al., 2011. Landscape ecology contributions to forestry and forest management in China: Progresses and research needs. In: Li C, Lafortezza R, Chen J Q (eds.). Landscape Ecology in Forest Management and Conservation. Beijing: Springer, Higher Education Press.

Matthews R B, Gilbert N G, Roach A et al., 2007. Agent-based land-use models: A review of applications. Landscape Ecology, 22: 1447-1459.

Medlyn B, Barton C, Broadmeadow M et al., 2001. Stomatal conductance of forest species after long-term exposure to elevated $\mathrm{CO}_{2}$ concentration: A synthesis. New Phytologist, 149: 247-264.

Mi Na, Yu Guirui, Wen Xuefa et al., 2008. Responses of subtropical conifer plantation to future climate change: A simulation study. Chinese Journal of Applied Ecology, 19(9): 1877-1883. (in Chinese)

Michaletz S T, Cheng D, Kerkhoff A J et al., 2014. Convergence of terrestrial plant production across global climate gradients. Nature, 512: 39-43.

Mickler R A, Earnhardt T S, Moore J A, 2002. Regional estimation of current and future forest biomass. Environmental Pollution, 116: S7-S16.

Mladenoff D J, He H S, 1999. Design and behavior of LANDIS, an object-oriented model of forest landscape disturbance and succession. In: Mladenoff D J, Baker W L (eds.). Spatial Modeling of Forest Landscape Change: Approaches and Applications. Cambridge: Cambridge University Press.

Nepstad D C, Stickler C M, Filho B S et al., 2008. Interactions among Amazon land use, forests and climate: Prospects for a near-term forest tipping point. Philosophical Transactions of the Royal Society B, 363: $1737-1746$.

Parmesan C, Yohe G, 2003. A globally coherent fingerprint of climate change impacts across natural systems. Nature, 421: 37-42.

Payette S, Filion L, Delwaide A et al., 1989. Reconstruction of tree-line vegetation response to long-term climate change. Nature, 341: 429-432.

Rounsevell M D A, Arneth A, Brown D G et al., 2012. Incorporating human behaviour and decision making processes in land use and climate system models. São José dos Campos: GLP Report No.7. GLP-IPO.

Rudel T K, Coomes O T, Moran E et al., 2005. Forest transitions: Towards a global understanding of land use 
change. Global Environmental Change, 15: 23-31.

Scheller R M, Domingo J B, Sturtevant B R et al., 2007. Design, development, and application of LANDIS-II, a spatial landscape simulation model with flexible temporal and spatial resolution. Ecological Modelling, 201: 409-419.

Scheller R M, Mladenoff D J, 2004. A forest growth and biomass module for a landscape simulation model, LANDIS: Design, validation, and application. Ecological Modelling, 180: 211-229.

Scheller R M, Mladenoff D J, 2005. A spatially interactive simulation of climate change, harvesting, wind, and tree species migration and projected changes to forest composition and biomass in northern Wisconsin, USA. Global Change Biology, 11: 307-321.

Schindler D E, Hilborn R, 2015. Sustainability: Prediction, precaution, and policy under global change. Science, 347: 953-954.

Schröter D, Acosta-Michlik L, Arnell A W et al., 2004. ATEAM Final Report 2004. Potsdam: Potsdam Institute for Climate Impact Research.

Schröter D, Cramer W, Leemans R et al., 2005. Ecosystem service supply and vulnerability to global change in Europe. Science, 310: 1333-1337.

Sheng Wenping, Ren Shujie, Yu Guirui et al., 2011. Patterns and driving factors of WUE and NUE in natural forest ecosystems along the North-South Transect of Eastern China. Journal of Geographical Sciences, 21: 651-665.

Tebaldi C, Knutti R, 2007. The use of the multi-model ensemble in probabilistic climate projections. Philosophical Transactions of the Royal Society A: Mathematical, Physical and Engineering Sciences, 365: 2053-2075.

Thompson J R, Foster D R, Scheller R M et al., 2011. The influence of land use and climate change on forest biomass and composition in Massachusetts, USA. Ecological Applications, 21: 2425-2444.

Thompson J R, Simons-Legaard E, Legaard K et al., 2016. A LANDIS-II extension for incorporating land use and other disturbances. Environmental Modelling \& Software, 75: 202-205.

Wang Yidong, Li Qingkang, Wang Huimin et al., 2011. Precipitation frequency controls interannual variation of soil respiration by affecting soil moisture in a subtropical forest plantation. Canadian Journal of Forest Research, 41: 1897-1906.

Wittig V E, Bernacchi C J, Zhu X G et al., 2005. Gross primary production is stimulated for three Populus species grown under free-air $\mathrm{CO}_{2}$ enrichment from planting through canopy closure. Global Change Biology, 11: 644-656.

Wu Dan, Shao Quanqin, Liu Jiyuan et al., 2011. Spatiotemporal dynamics of forest carbon storage in Taihe County of Jiangxi Province in 1985-2030. Chinese Journal of Applied Ecology, 22(1): 41-46. (in Chinese)

Wu Zhonglun, 1984. Chinese Fir. Beijing: China Forestry Publishing House. (in Chinese)

Xu C G, Gertner G Z, Scheller R M, 2007. Potential effects of interaction between $\mathrm{CO}_{2}$ and temperature on forest landscape response to global warming. Global Change Biology, 13: 1469-1483.

Xu C G, Gertner G Z, Scheller R M, 2009. Uncertainties in the response of a forest landscape to global climatic change. Global Change Biology, 15: 116-131.

Xu C G, Gertner G Z, Scheller R M, 2011. Importance of colonization and competition in forest landscape response to global climatic change. Climatic Change, 110: 53-83.

Yu Qiangyi, Wu Wenbin, Tang Huajun et al., 2011. Complex system theory and agent-based modeling: Progresses in land change science. Acta Geographica Sinica, 66(11): 1518-1530. (in Chinese)

Yu Quanzhou, Wang Shaoqiang, Shi Hao et al., 2014. An evaluation of spaceborne imaging spectrometry for estimation of forest canopy nitrogen concentration in a subtropical conifer plantation of southern China. Journal of Resources and Ecology, 5(1): 1-10. 